\title{
PRIKAZ I ZASTUPLJENOST UPOTREBE KONCEPTA FER VREDNOSTI U KOMPANIJAMA KOJE SE KOTIRAJU NA BEOGRADSKOJ BERZI
}

\section{Mirjana Mijoković}

Univerzitet Singidunum Beograd, Srbija

\begin{abstract}
Apstrakt:
Cilj ovog istraživanja je da pruži doprinos postojećoj literaturi kada je u pitanju upotreba metoda fer vrednosti kao osnovice za vrednovanje nekretnina, postrojenja i opreme. Analiziran je i uticaj ovog metoda na poslovanje javnih akcionarskih društava. Predmet istraživanja je analiza primene metode fer vrednosti u javnim akcionaskim društavima, čije se akcije kotiraju na Beogradskoj berzi. Uzorak istraživanja čini 312 akcinarskih društava iz različitih oblasti privređivanja koja su listirana na pomenutoj berzi 16.10.2015. godine. Javna akcionarska društva koja čine uzorak istraživanja odabrana su metodom slučajnog uzorka. Sprovedeno istraživanje, pokazalo je da oko $82 \%$ akcionarskih društava sa Beogradske berze koristi model nabavne vrednosti pri naknadnoj proceni vrednosti nekretnina, postrojenja i opreme, dok oko $14 \%$ koristi model fer vrednosti.
\end{abstract}

Ključne reči:

nabavna vrednost, fer vrednost, berza, akcionarsko društvo,akcije.
Korespondencija:

Mirjana Mijoković

e-mail:

mirjana.mijokovic.12@singimail.rs
UVOD

Razvoj društva je doveo do centralizacije kapitala, naročito u industriji i bankarstvu. Jedan od veoma rasprostranjenih oblika te centralizacije su akcionarska društva. Velika privredna društva u kapitalističkim zemljama imaju oblik akcionarskih društava. U drugoj polovini devetnaestog veka, rasprostranjenost akcionarskih društava sve više uzima maha. Oblik investicionog privrednog društva je akcionarsko društvo, čiji kapital je nastao ulaganjem male ili velike sume novca brojnih investitora, koji postaju vlasnici određenog broja akcija, u odnosu na uloženi novac. Hartija od vrednosti je akcija koja predstavlja deo kapitala akcionarskog društva čije posedovanje vlasniku daje određena prava. Na osnovu stečenog vlasništva nad akcijama, vlasnik akcija, ima pravo na odgovarajući deo profita koji je izražen kroz dividendu i pravo učešća u upravljanju društvom, što zavisi od toga kojom vrstom akcija akcionar raspolaže. Pravilima akcionarskog društva se utvrđuje akcijski kapital koji je podeljen na određeni broj akcija.

Javna akcionarska društva formiraju kapital prodajom i emitovanjem akcija (običnih - redovnih i povlašćenih - prioritetnih). Strukturu kapitala akcionarskih društava čine sopstven i osnovni kapital. Sopstveni kapital predstavlja širi pojam od osnovnog kapitala i čine ga neraspoređena i preneta dobit, rezerve, ažio i osnovni kapital. Osnovni kapital čine akcijski kapital po osnovu redovnih akcija i akcijski kapital po osnovu prioritetnih akcija, a njegov minimalni iznos je zakonski propisan (Jovanović, 2007).

Berza je organizovano mesto trgovanja, koje je regulisano propisima i pravilima, služi za spajanje naloga kupaca i prodavaca hartija od vrednosti. Članovi berze treba da zadovolje uslove koji su postavljeni, kako bi dobili odobrenje za članstvo od strane organa berze. Dileri trguju u svoje ime i za svoj račun, dok brokeri trguju za račun drugih. $\mathrm{Na}$ berzi se vrši isključivo trgovina hartijama od vrednosti, ona predstavlja organizovano tržište hartija od vrednosti (Hadžić, 2013). Izlaskom na berzu akcionarsko društvo 
dobija besplatnu reklamu, jer na taj način postaje poznato široj javnosti. U medijima se objavljuju podaci o njegovom poslovanju, ali i cene njegovih akcija. Kada je broj prodavaca i kupaca dovoljno veliki tržište je savršeno efikasno, ali ako se posmatra celo tržište broj prodavaca i kupaca je mali, što znači da oni ne mogu odlučujuće uticati na cene i njihovo kretanje. Likvidno tržište je efikasno tržište, što znači da ima širinu, dubinu i elastičnost (Jeremić, 2013). Listirane akcije na berzi akcionarskom društvu mogu da posluže kao marketing poruka. U odnosu na obveznice, akcije kao hartije od vrednosti sa većim rizikom ali i donose veći prinos. Obveznice koje su visoko rangirane donose niže prinose ali su i manje rizične hartije od vrednosti u odnosu na akcije, zbog visokog stepena sigurnosti investitora da će obaveze biti isplaćene u roku. Kako bi se prilikom emitovanja akcija privukli investitori i kako bi se nadoknadio rizik ulaganja, veću kamatu imaju obveznice sa nižim stepenom sigurnosti u rangiranju (Jeremić, 2013).

Predmet istraživanja ovog rada je analiza primene metode fer vrednosti u praksi, kao i kotiranje akcija privrednih društava na Beogradskoj berzi. Uzorak istraživanja obuhva 312 javnih akcionarskih društava koja se bave ražličitim oblastima privređivanja, i koja su listirana 16.10.2015. godine. Akcionarska društva koja su predmet istraživanja, odabrana su metodom slučajnog uzorka. Temelje razvoja ekonomije jedne države predstavljaju javna akcionarska društva, koja imaju brojne prednosti u odnosu na sve ostale pravne forme privrednih društava. Uvećanje sopstvenog kapitala je jedna od tih prednosti, bez dodatnog zaduživanja iz pozajmljenih izvora.

\section{OSNOVNE KARAKTERISTIKE MODELA FER VREDNOSTI}

\section{Definicija fer vrednosti}

Fer vrednost predstavlja cenu koja se može dobiti prilikom prodaje imovine, odnosno cenu za prenos obaveze $\mathrm{u}$ redovnoj transakciji na tržištu na dan vrednovanja između učesnika. Ovo je cena koja se plaća pri kupovini imovine, a predstavlja izlaznu cenu koja je suprotnost ulaznoj ceni. Karakteristike koje razmatraju učesnici na tržištu odnose se na utvrđivanje fer vrednosti sredstava i obaveza. U slučaju imovine, ove karakteristike se odnose na lokaciju i stanje nekretnine, kao i na svako ograničenje koje se odnosi na njeno korišćenje ili prodaju. Na osnovu mišljenja entiteta o vrednosti, na tržištima koja beleže pad, cene mogu biti na nižem nivou u odnosu na cene iz prošlosti (Jovanović, 2011).

Standard koji definiše fer vrednost je Međunarodni standard finansijskog izveštavanja 13 (MSFI 13). Prikaz ovog standarda, učinjen je na osnovu izvornog teksta ovog standarda, ali i na osnovu literature koja se takođe poziva na ovaj standard.
U radu istražujemo da li uzorkovana privredna društva primenjuju vrednovanje nekretnina, postrojenja i opreme privrednog društva po konceptu nabavne ili fer vrednosti. Međunarodni standard finansijskog izveštavanja 13 - Merenje fer vrednosti, definiše fer vrednost kao cenu koja bi se dobila za prodaju imovine, ili koja bi se platila za prenos obaveza prilikom redovne transakcije na datum odmeravanja snaga između učesnika na tržištu (IASB, 2014). Razmena se obavlja pod tržišnim ili komercijalnim uslovima. Iznos vrednovanja obaveza utvrđuje se na isti način. Pored sudova i procenitelja, fer tržišnu vrednost koriste i mnoge kontrolne i regulativne institucije, $\mathrm{u}$ oblasti računovodstva i finansijskog izveštavanja (Poznanić \& Cvijanović, 2011). Stvarnu fakturnu vrednost predstavlja nabavna vrednost kojoj se dodaju zavisni troškovi nabavke.

Računovodstveni standardi o načinu sastavljanja i prikazivanja finansijskih izveštaja i računovodstvenog obuhvatanja transakcija predstavljaju obavezujuća pravila. MSFI se primenjuju na prikazivanje i sastavljanje finansijskih izveštaja opšte namene privrednih subjekata, a njihove aktivnosti su usmerene ka ostvarivanju dobiti. Standardi se bave:

1. vrednovanjem i priznavanjem elemenata u finansijskim izveštajima,

2. prikazivanjem i obelodanjivanjem elemenata finansijskog izveštaja (Petrović, 2013).

A) U Određenom vremenskom periodu kojim se obuhvata priznavanje elemenata finansijskog izveštaja koji se odnose na sredstva, utvrđuje se da li se neka transakcija nalazi u bilansu uspeha ili bilansu stanja finansijskog izveštaja (na primer privredno društvo je pribavilo autobus, koji će biti korišćen kao prevozno sredstvo, potrebno je da odredimo da li je to ulaganje za privredno društvo rashod ili sredstvo). Standardi razlikuju dve vrste priznavanja:

- Početno priznavanje - radi se o priznavanju kada se neka stavka uvodi u poslovne knjige (na primer prilikom kupovine sredstava);

- Naknadno priznavanje - vezano je za stavku o priznavanju koja već postoji u finansijskim izveštajima. Primenjuje se kada u toku godine nastane neki poslovni događaj koji se odnosi na postojeću stavku (na primer stvaranje dodatnih troškova), a na kraju poslovne godine se proverava da li postojeće stavke ispunjavaju uslove za priznavanje.

B) U odnosu knjiženje, vrednovanje obuhvata određivanje iznosa, na primer vrednovanje procesa proizvodnje troškova materijala. $U$ zavisnosti od trenutka kada se vrši, vrednovanje može biti naknadno i početno:

- Početno vrednovanje - obuhvata vrednost koja se po prvi put unosi u poslovne knjige (na našem primeru nabavna vrednost autobusa). 
- Naknadno vrednovanje - predstavlja određivanje vrednosti stavke koja postoji u finansijskim izveštajima (na primer možemo vrednovati autobus primenom fer vrednosti). Naknadno vrednovanje podrazumeva i donošenje odluke o tome da li će dodatni troškovi, koji su nastali upotrebom sredstva, biti uračunati u njegovu vrednost ili će biti predstavljeni kao rashodi (na primer možemo zameniti deo manje vrednosti ili zameniti motor).

C) Prezentovanje podrazumeva prikazivanje pozicija u finansijskim izveštajima ili u napomenama. Predstavlja se u vidu tabela ili pomoću teksta.

D) Objavljivanje (obelodanjivanje) je postupak kojim se finansijskim izveštajima u pisanoj formi daju dodatna obrazloženja. Objavljivanje podrazumeva i obelodanjivanje računovodstvenih politika, koje se koriste u finansijskom izveštavanju i sastavljanju finansijskih izveštaja.

\section{Osnovice za vrednovanje}

Računovodstvo vekovima predstavlja jedan od faktora stabilizacije svetske ekonomije. Privredna društva koja primenjuju Međunarodne računovodstvene standarde imaju kvalitetnije računovodstvo, niže troškove kapitala, blagovremeno prepoznaju gubitke, dok su knjigovodstveni iznosi relevantniji i imaju veću važnost (Barth et al., 2008). Može se primetiti da je svetska finansijska kriza imala manji uticaj na evropske zemlje, nego na Sjedinjene Američke Države (Škarić-Jovanović, 2009). Mnogi autori, među kojima je i profesorka računovodstva Barth (2008), ukazuju na značaj Međunarodnih standarda finansijskog izveštavanja (MSFI) i sugerišu da bi SAD trebalo da uvede MSFI, kao neku vrstu dopune opšte prihvaćenih računovodstvenih principa (GAAP). Kada je bilans stanja precenjen, tada ukupno povećanje vrednosti aktive može da se koristi za nova zaduženja. Bilans uspeha može da prikaže profit i gubitke koji neće biti realizovani. Princip pouzdanosti se obično tumači kao kvalitet informacija koji garantuje nepostojanje grešaka i verno predstavlja ono što se od njega očekuje. U normalnim tržišnim uslovima fer vrednost, kao tržišna vrednost, bi trebalo da predstavlja vernu procenu. Kada postoji nedostatak transakcije sličnih sredstava, subjektivne prognoze i procene uprave su neophodne za nelikvidna tržišta. Ovo bi moglo da dovede do pogrešnih proračuna procenjene vrednosti i manipulacije (Stanišić et al., 2013).

Pojava krize u kreditno-štednim institucijama u SAD-u, istorijski trošak ili nabavna vrednost pri porastu rizika finansiranja, dala je iskrivljenu sliku vrednosti finansijske aktive koja je ovim institucijama bila na raspolaganju, što je navelo investitore da pogrešno procenjuju vrednost njihovog kapitala, a to je prouzrokovalo netačnu procenu rizika likvidnosti.
Korišćenjem nabavne vrednosti, odnosno istorijskog troška, prikazana je ona vrednost koju su finansijski instrumenti imali u trenutku nabavke, što je predstavljalo daleko veću vrednost od vrednosti koju su ti instrumenti imali na tržištu, vrednovani po tržišnim cenama. Precenjena vrednost aktive predstavlja veliki problem za većinu investitora. One vrednosti koje bi, pod određenim uslovima, trebalo da obezbeđuju pošteno vrednovanje imovine ili obaveza podrazumevaju fer vrednosti.

Osnovice vrednovanja mogu biti različite i to:

- Fakturna vrednost - predstavlja proizvod nabavljene količine i fakturne cene;

- Nabavna vrednost - predstavlja zbir zavisnih troškova nabavke fakturne vrednosti. Zavisni troškovi se pomoću dva ključa raspoređuju na pojedine vrste zaliha: težina (istovar, prevoz, utovar); fakturna vrednost (osiguranje i provizija);

- Cena koštanja obuhvata zbir svih troškova koji su nastali stvaranjem određenih učinaka u vezi proizvodnje i prodaje (Petrović, 2012). U zavisnosti od toga da li su u cenu koštanja uračunati troškovi prodaje i proizvodnje, ili samo troškovi proizvodnje, razlikujemo: proizvodnu cenu koštanja i prodajnu cenu koštanja.

- Istorijski trošak - hronološki posmatrano, model istorijskog troška prethodi konceptu fer vrednosti i bazira se na ceni koštanja ili nabavnoj vrednosti.

- Fer vrednost - poštena, pravična, ili fer vrednost se definiše kao vrednost po kojoj neku imovinu možemo prodati, a obavezu izmiriti u nezavisnoj transakciji između obaveštenih i voljnih strana (IASB, 2014).

- Rezidualna vrednost predstavlja prodajnu vrednost nekog sredstva, nakon što to sredstvo bude u potpunosti amortizovano.

- Nadoknadivi iznos predstavlja fer vrednost ili upotrebnu vrednost u zavisnosti od toga koja od ovih vrednost je veća, umanjeno za troškove prodaje (MRS 16).

Upotrebna vrednost ili korisni vek je vremenski period u kojem je sredstvo raspoloživo za upotrebu; predstavlja broj proizvodnih jedinica koje bi to sredstvo trebalo da proizvede (MRS 16).

Početna vrednost se može meriti po ceni koštanja i po nabavnoj vrednosti. Stvarna fakturna vrednost obuhvata nabavnu vrednost kojoj se dodaju zavisni troškovi nabavke. Zavisni troškovi se raspoređuju na pojedine vrste zaliha tako što se koriste dva elementa za lokaciju ovih troškova(Jovanović, 2007):

- Težina (istovar, prevoz, utovar),

- Fakturna vrednost (osiguranje i provizija).

Kada koristimo nabavnu vrednost treba naglasiti da fakturna vrednost može biti umanjena za komercijalne popuste (bonifikacija i rabat): 
- Bonifikacija je sniženje cene od strane dobavljača, zato što smo dobili robu koja je lošijeg kvaliteta od ugovorenog;

- Rabat je trgovački (komercijalni) popust koji se odobrava u dva oblika: kao količinski rabat (u slučaju kada se kupuje velika količinu robe) i kao sezonskog rabat (u sličaju kada se kupuje roba van sezone).

Bonifikacija i rabat se knjigovodstveno isto tretiraju.

- Finansijski popust (kasa skonto): popust koji dobavljač odobrava kupcu za plaćanje pre roka dospeća obaveze je kasa skonto. To je kamata koju dobavljač plaća kupcu, za korišćenje njegovog novca, od momenta dospeća obaveze do momenta plaćanja i on ne znači smanjenje cene. Jedini način da se iskoristi odobreni kasa skonto, koji je samo obaveštenje, je da se izvrši plaćanje u dogovorenom roku (popust na kasi). Izmirenje postojećih obaveza sa manjom količinom novca je suština kasa skonto.

\section{Merenje fer vrednosti}

U uslovima istorijskog troška fer vrednost se primenjivala u okviru primene principa niže i više vrednosti, a u stvari prilikom primene načela impariteta. Računovodstvo fer vrednosti podrazumeva svakodnevnu, kontinuiranu, a ne sporadičnu upotrebu fer vrednosti, kao što je to slučaj kod koncepta istorijskog troška. Dolazi se do zaključka da računovodstvo fer vrednosti znači kontinuiranu upotrebu fer vrednosti, dok povremenu upotrebu fer vrednosti predstavlja koncept fer vrednosti.

Za prezentaciju i sastavljanje finansijskih izveštaja koriste se informacije koje su potrebne korisnicima. Četiri osnovne karakteristike finansijskih izveštaja su: pouzdanost, relevantnost, razumljivost i uporedivost. Relevantna informacija utiče na ekonomske odluke korisnika, i pomaže prilikom procene budućih, sadašnjih i prošlih događaja.

Poznavanje koncepta istorijskog troška i računovodstva fer vrednosti predstavlja osnovu za njihovo razumevanje. Znanje računovodstva koje je bazirano na konceptu istorijskog troška postalo je nedovoljno prilikom uvođenja normativne osnove računovodstva fer vrednosti (Jovanović, 2012).

Prilikom uvođenja finansijskog izveštavanja, koncept fer vrednosti postaje predmet brojnih rasprava. Svako uvođenje nove prakse, odnosno pravila, dovodi do uobičajenog otpora, ukoliko postoji duga tradicija kao što je to slučaj sa finansijskim izveštavanjem. Finansijska kriza je izazvala kritike na račun koncepta fer vrednosti, što je dovelo do zahteva da se odustane od primene fer vrednosti ili da se ona suspenduje (Jovanović, 2009).
Računovodstvo fer vrednosti bilo je predmet ozbiljnih, ali ne i brojnih kritika. Zbog nedostatka ubedljivih empirijskih dokaza o njegovim inherentnim slabostima, te kritike su olako odbacivane i osporavane. Svetska finansijska kriza koja je u septembru 2008. godine počela slomom finansijskih tržišta u SAD, bila je jedan od povoda za preispitivanje računovodstva fer vrednosti. Slomom finansijskog tržišta SAD-a, finansijski instrumenti brojnih globalnih korporacija postali su bezvredni, jer su bili procenjeni po fer vrednosti koja je pružila brojne podatke koje je bilo potrebno preispitati (Stojilković, 2010). Kao nedostatak računovodstva fer vrednosti navode se pogrešne ciljne orijentacije godišnjih finansijskih izveštaja koji su zasnovani na fer vrednosti. Načela urednog balansiranja su u sukobu sa konceptom fer vrednosti (Stojilković, 2011).

Prilikom odmeravanja fer vrednosti inputi procene se svrstavaju u tri nivoa. Navedena hijerarhija daje prioritet kotiranim cenama na aktivnim tržištima za ista sredstva ili obaveze (inputi prvog nivoa), dok najmanji prioritet daje neprimetnim inputima trećeg nivoa:

- Nivo 1 obuhvata kotirane tržišne cene na aktivnom tržištu za obveznice i akcije, na primer sa listinga Beogradske berze;

- Nivo 2 obuhvata inpute sredstava ili obaveza, bilo direktno ili indirektno. Inputi drugog nivoa uključuju kotirane cene za slična sredstva ili obaveze na aktivnom tržištu, kotirane cene za identičnu ili sličnu imovinu ili obaveze na tržištima koja nisu aktivna.

- Nivo 3 predstavlja one inpute koji su deo odluke i procene samog menadžmenta, dok tržišni učesnici koriste parametre, kako bi došli do cene nekog finansijskog instrumenta. Inputi trećeg nivoa su neuočljivi inputi za sredstva ili obaveze, koje bi trebalo primeniti za odmeravanje fer vrednosti, kada relevantni inputi nisu dostupni i uočljivi.

Razvoj privrede u velikoj meri zavisi od stabilnosti finansijskih tržišnih struktura, tako da je potpuna stabilnost finansijskog sistema cilj državnih organa. U suprotnom, ekonomija jednostavno neće biti u stanju da se prirodno oporavi od finansijske krize. Ograničavanjem kredita, banke su optužene za onemogućavanje ekonomskog oporavka. Međutim, stečaj nekog velikog fonda ili finansijske korporacije nikada se nije dogodio istog dana. Kao pobornik fer vrednosti, Blumberg je rekao da se one teško ostvaruju na tržištu, ukoliko postoji visok faktor straha, nedostatak samopouzdanja i likvidnosti (Hajek et al., 2015). Primena fer vrednosti predstavlja računovodstveni metod koji je privatno potpomognut hipotekarnim obveznicama, što može biti problematično u datom trenutku. Zaista je teško dobiti dobru tržišnu fer vrednost, jer je mali procenat hipotekarnih obveznica namenjen trgovini (Hajek et al., 2015). Da bi doneli racionalne ekonomske odluke, korisnici finansijskih informacija očekuju pouzdane finansijske izveštaje. Pored pozitivnih očekivanja, savremeni 
poslovni ambijent karakterišu različite nepravilnosti u poslovanju, nepoštovanje profesionalne i zakonske računovodstvene regulative, kao i sprovođenje neadekvatne računovodstvene tehnike.

\section{REZULTATI I METODOLOGIJA ISTRAŽIVANJA}

U ovom istraživanju ćemo saznati da li uzorkovana privredna društva vrše naknadno vrednovanje imovine privrednog društva po konceptu fer vrednosti ili nabavne vrednosti. Cilj ovog istraživanja je analiza finansijskih izveštaja akcionarskih društava koja su kotirana na Beogradskoj berzi sa aspekta upotrebe određenih metoda naknadnog vrednovanja nekretnina, postrojenja i opreme. U tabeli 1 prikazane su osnovne finansijske informacije o uzorkovanim akcionarskim društvima. Uzorak sadrži 312 kotiranih kompanija.

Statistika činjenica predstavljena je u nominalnom obliku. Brojni su primeri u kojima su statističke vrednosti izražene u procentima. Prosek je najrasprostranjeniji način predstavljanja podataka kojim može da se predstavi grupa ili količina brojeva. Najrasprostranjenija je aritmetička sredina, medijana i modus. Srednja vrednost je zbir svih stavki u grupi podeljen sa brojem stavki u grupi. Koristi se kada želimo da uporedimo samo jednu stavku, ili pojedinačnu vrednost sa grupom. Prednost srednje vrednosti je njena jednostavnost i brzina obračuna. Nedostatak proseka je u tome što u slučaju ekstremnih vrednosti daje iskrivljenu sliku. Medijana je srednja tačka, od koje je polovina brojeva manja, a druga polovina veća. Kada imamo neparan broj elemenata medijana se nalazi tako što deli seriju tačno na pola; ako je broj elemenata paran, dva srednja broja podeljena na pola predstavljaju medijanu. Često je veoma teško da se veliki broj elemenata organizuje po veličini. Modus je broj koji se najčešće pojavljuje u seriji podataka ili zapažanja i pokazuje najčešću veličinu ili iznos. Na modus ne utiče pojava ekstremnih vrednosti, a kada je ukupan broj posmatranja mali, modus ne bi trebalo koristiti. Ako se jedan element pojavljuje samo jednom u posmatranoj seriji, modus ne postoji. Kod simetričnog rasporeda, iznosi prosečne vrednosti, medijane i modusa su međusobno jednaki. Kod pozitivne asimetrije prosečna vrednost se pomera od modusa prema većim vrednostima obeležja, dok se kod negativne asimetrije prosečna vrednost pomera od modusa ka manjim vrednostima obeležja (Žižić et al., 2007)

U toku ovog istraživanja pojavila su se brojna ograničenja. Finansijski izveštaji za 2014. godinu su bili nedostupni, kao i podaci određenog broja hartija od vrednosti sa Beogradske berze. Kvantitativne informacije su sadržane samo u napomenama u vidu vrednosti imovine izražene u novčanim jedinicama mere, dok su izostale kvalitativne informacije. Određene vrednosti u napomenama nisu precizno i jasno navedene.

Istraživanje je bazirano na tri elementa: prosečna vrednost ukupne imovine, prosečna vrednost dobiti i prosečna vrednost EBIT-a. Dobijene prosečne vrednosti prikazane su u tabeli 1 .

$\mathrm{Na}$ osnovu izračunatih vrednosti može se zaključiti da je prosečna vrednost i medijana za ukupnu imovinu privrednih društava u 2014. godini bila veća nego u 2013. godini. Prosečna vrednost neto rezultata se smanjila u 2014. godini u odnosu na 2013. godinu, a medijana je veća za 2014. godinu u odnosu na 2013. godinu. Prosečna vrednost EBIT-a u 2013. godini bila je veća nego 2014. godine što se uočava i za medijanu. Može se uočiti da su prosečne vrednosti veće od medijana za 2013. i 2014. godinu za ukupnu imovinu, neto rezultat i EBIT, što predstavlja pozitivan asimetričan raspored. Veličina pravnih lica se utvrđuje na osnovu ukupne imovine i EBIT-a.

Godišnji finansijski izveštaji predstavljaju značajan izvor informacija za analizu razvoja privrednih društava. Pouzdanost ima značajnu ulogu u analizi finansijskih izveštaja, a ona zavisi od ažurnosti knjigovodstva, tačnosti uprave privrednih društava i primene računovodstvenih standarda. Akcionari privrednih društava (vlasnici) predstavljaju najzainteresovanije korisnike finansijskih izveštaja, među kojima su dobavljači, kupci akcija, banke, mogući investitori, državni organi i zaposleni.

Tabela 1. Prosečne vrednosti i medijane ukupne imovine, neto rezultat i EBIT uzorkovanih privrednih društava

\begin{tabular}{|c|c|c|c|c|c|c|c|c|c|c|c|c|}
\hline & \multicolumn{4}{|c|}{$\begin{array}{l}\text { Ukupna imovina u hiljadama } \\
\text { dinara }\end{array}$} & \multicolumn{4}{|c|}{ Neto rezultat u hiljadama dinara } & \multicolumn{4}{|c|}{ EBIT u hiljadama dinara } \\
\hline \multirow{2}{*}{$\begin{array}{l}\text { Broj } \\
\text { privrednih } \\
\text { društava }\end{array}$} & \multicolumn{2}{|c|}{$\begin{array}{l}\text { Prosečne vred- } \\
\text { nosti }\end{array}$} & \multicolumn{2}{|c|}{ Medijana } & \multicolumn{2}{|c|}{$\begin{array}{l}\text { Prosečne vred- } \\
\text { nosti }\end{array}$} & \multicolumn{2}{|c|}{ Medijana } & \multicolumn{2}{|c|}{$\begin{array}{l}\text { Prosečne vred- } \\
\text { nosti }\end{array}$} & \multicolumn{2}{|c|}{ Medijana } \\
\hline & 2013 & 2014 & 2013 & 2014 & 2013 & 2014 & 2013 & 2014 & 2013 & 2014 & 2013 & 2014 \\
\hline UKUPNO & \multirow[b]{2}{*}{2.479} & \multirow[b]{2}{*}{2.633} & \multirow[b]{2}{*}{386} & \multirow[b]{2}{*}{431} & \multirow[b]{2}{*}{228.556} & \multirow[b]{2}{*}{172.291} & \multirow[b]{2}{*}{4.768} & \multirow[b]{2}{*}{5.120} & \multirow[b]{2}{*}{287.117} & \multirow[b]{2}{*}{224.811} & \multirow[b]{2}{*}{14.147} & \multirow[b]{2}{*}{10.754} \\
\hline & & & & & & & & & & & & \\
\hline
\end{tabular}


U tabeli 2 prikazani su rezultati istraživanja o učešću primene fer vrednosti i nabavne vrednosti privrednih društava kotiranih na Beogradskoj berzi.

Tabela 2. Uzorkovana javna društva prema metodi naknadnog vrednovanja nekretnina, postrojenja i opreme

\begin{tabular}{lcc}
\hline & Nekretnine, postrojenja i oprema \\
\hline Izveštajni periodi & 2013 & 2014 \\
\hline Fer vrednost & 42 & 41 \\
\hline Nabavna vrednost & 257 & 257 \\
\hline Nije dostupno & 13 & 14 \\
\hline UKUPNO & 312 & 312 \\
\hline
\end{tabular}

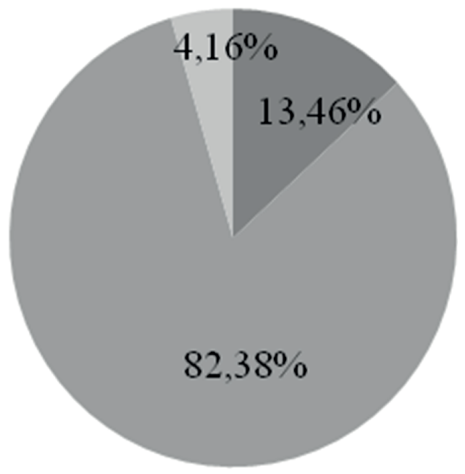

\section{Fer vrednost \\ Nabavna \\ vrednost \\ Nije dostupno \\ 2013. godina}

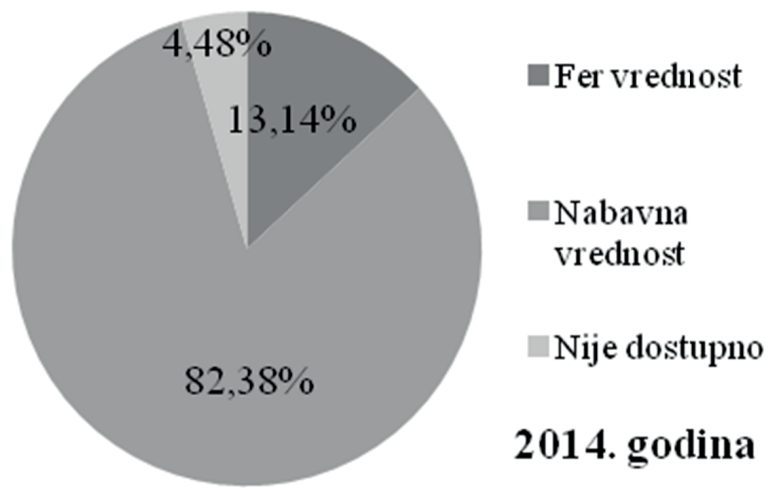

Slika 1. Prikaz upotrebe koncepta fer vrednosti, nabavne vrednosti na uzorkovanim privrednim društvima za 2013. i 2014. godinu - izveštajni period

Na osnovu dobijenih podataka, može se zaključiti da privredna društva koja se kotiraju na Beogradskoj berzi najviše primenjuju nabavnu vrednost oko $82 \%$, a fer vrednost koriste u manjem obimu oko $14 \%$. Podaci koji nisu bili dostupni procentualno su mali 4,16\% za 2013. godinu i 4,48\% za 2014. godinu, i ne utiču negativno na rezultate ovog istraživanja. Sa aspekta promene metode, u 2013. i 2014. godini, nije bilo značajnih promena.

\section{ZAKLJUČAK}

Nakon ovog istraživanja zaključeno je da privredna društva čije se akcije kotiraju na Beogradskoj berzi više primenjuju nabavnu vrednost $82,38 \%$, u odnosu na fer vrednost koja se kreće između 13,14\% i 13,46\%. Takođe, uočeno je da postoji pozitivan asimetričan raspored, jer su prosečne vrednosti veće od medijana za 2013. i 2014. godinu za ukupnu imovinu, neto rezultat i EBIT. Smatra se da bi fer vrednost trebalo da bude više zastupljena, jer bi pomogla investitorima da lakše odluče prilikom kupovine kotiranih akcija sa znatno manje rizika. Ali treba imati u vidu da model fer vrednosti može negativno uticati na ciklične privredne uslove i pojačati negativne efekte krize (Mizdrakovic \& Stanisic, 2016). Finansijski i imovinski položaj privrednog društva predstavlja nameru fer vrednosti da se približi realnosti, kako bi se u bilansu stanja prikazao realan imovinski i finansijski položaj koji će investitorima pružiti stvarno stanje o njihovoj imovini. Racionalni investitor želi da investira uz najoptimalniji odnos prinosa i rizika, jer veliki rizik može da donese veliki dobitak, ali postoji mogućnost apsolutnog gubitka.

\section{LITERATURA}

Barth, M., Landsman, W., \& Lang, M. (2008). International Accounting Standards and Accounting Quality. Journal of Accounting Research, 46(3), 467-498. doi: 10.1111/j.1475679X.2008.00287.x

Hadžić, M. (2013.). Bankarstvo. Beograd: Univerzitet Singidunum. Hajek, P., Maitah, M., \& Čadil, J. (2015, July). Destabilizing Effects of Fair Value Accounting During US Banking Crisis. Reviev of European Studies, 7(11), 222-231. doi:10.5539/ res.v7n11p222

IASB. (2014). Međunarodni standard finansijskog izveštavanja 13 - Merenje fer vrednosti. Tratto da Deloitte: http://www2. deloitte.com/hr/hr/pages/audit/articles/ifrs-news-2014-06. html

Jeremić, Z. (2013). Finansijska tržišta i finansijski posrednici. Beograd: Univerzitet Singidunum.

Jovanović, K. (2007). Finansijsko računovodstvo. Beograd: Centar za izdavačku delatnost Ekonomskog fakulteta.

Jovanović, K. (2009). Finansijska kriza-povod za preispitivanje osnova vrednovanja u finansijskim izveštajima. 40. Simpozijum 40 godina računovodstva i poslovnih finansija - dometi i perspektive (p. 414-432). Zlatibor: Beograd: Savez računovođa i revizora.

Jovanović, K. (2011). Izmjene u definiciji fer vrijednosti i hijerarhijski nivoi fer vrijednost prema MSFI 13-mjerenje fer vrijednostii. Finrar, (str. 5-10). Banja Vrućica.

Jovanović, K. (2012). Implikacije primene fer vrednosti na iskaznu moć izveštaja o rezultatu. Zbornik radova 43. Simpozijuma (str. 21-43). Zlatibor: Savez računovođa i revizora Republike Srbije.

Mizdrakovic, V., \& Stanisic, N. (2016). Revisiting Fair Value Accounting as Magnifier of Financial Crises. International Scientific Conference Sinteza (pp. 382-388). Beograd: Singidunum University. doi:10.15308/Sinteza-2016-382-388 
Petrović, Z. (2012). Upravljačko računovodstvo. Beograd: Univerzitet Singidunum.

Petrović, Z. (2013). Finansijsko izveštavanje. Beograd: Univerzitet Singidunum.

Poznanić, V., \& Cvijanović, J. (2011). Metode vrednovanja preduzeća. Beograd: Ekonomski institut.

Stanišić, N., Popović, S., Mizdraković, V., \& Djenić, M. (2013). Mark to Market Accounting as a Magnifier of Financial Crises. In R. Mirdala, Financial Aspects of Recent Trends in the Global Economy. 1st edition. (pp. 110-126). Craiova: ASERS Publishing.
Stojilković, M. (2010). Fair Value Accounting - The beginning of the End. Facta Universitatis, Series: Economics and Organization, 163-177.

Stojilković, M. (2011). Towards a criticism of Fair Value Accounting. Facta Universitatis, Series: Economics and Organization, 91-109.

Žižić, M., Lovrić, M., \& Pavličić, D. (2007). Metodi statističke analize. Beograd: Centar za izdavačku delatnost Ekonomskog fakulteta.

\section{REVIEW AND FREQUENCY OF FAIR VALUE CONCEPT APPLICATION IN COMPANIES LISTED ON BELGRADE STOCK EXCHANGE}

\section{Abstract:}

The objective of this research is to contribute to the existing literature regarding the use of fair value as the basis for the valuation of property, plant and equipment and the analysis of its impact on public companies' operations. The research topic is the analysis of the application of fair value method in those companies whose shares are listed on Belgrade Stock Exchange. The sample survey consists of the majority of the total of 312 companies from diverse economic fields, listed on the Stock Exchange on the date of 10/16/2015. Companies which form the research sample are selected randomly. In order to achieve the above-mentioned objective the research has been conducted. The results show that about $82 \%$ of the public companies on Belgrade Stock Exchange use the cost model for subsequent valuation of property, plant and equipment, whereas about $14 \%$ of them use the fair value model.

\section{Keywords:}

cost price,

stock exchange, public companies, shares. 